\title{
ARTICLE \\ Evidence-based treatment of systemic lupus erythematosus and its complications
}

\author{
B Hodkinson, ${ }^{1,2} \mathrm{MB}$ BCh, PhD, FCP (SA), Cert Rheumatology (SA); \\ M A Makda, ${ }^{2}$ MB BCh, FCP (SA), Cert Rheumatology (SA), MMed (Int Med) \\ ${ }^{1}$ Department of Medicine, Faculty of Health Sciences, Groote Schuur Hospital and University of Cape Town, South Africa \\ ${ }^{2}$ Division of Rheumatology, Department of Internal Medicine, Chris Hani Baragwanath Academic Hospital, Faculty of Health Sciences, \\ University of the Witwatersrand, Johannesburg, South Africa
}

Corresponding author: B Hodkinson (drbridget@gmail.com)

\begin{abstract}
Outcomes for patients with systemic lupus erythematosus (SLE) have improved during the last two decades as our understanding of the disease expands. In particular, the importance of antimalarial therapy for addressing and preventing a host of complications in SLE has emerged. Furthermore, evidence is mounting that corticosteroids, while offering excellent control of disease activity, are responsible for many of the late complications of SLE and need to be prescribed in modest doses for the shortest time possible. To achieve this, an understanding of the available 'steroid-sparing' immunosuppressants is useful. Specific attention needs to be paid to the two most important complications of SLE, i.e. infections and atherosclerotic cardiovascular events. Awareness of, screening for and aggressive management of risk factors for these comorbidities are paramount.
\end{abstract}

S Afr Med J 2015;105(12):1075. DOI:10.7196/SAMJ.2015.v105i12.10221

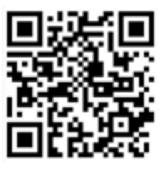

\section{Rationale for this review}

Ideally, all systemic lupus erythematosus (SLE) patients should be reviewed by a specialist. Early referral to a rheumatologist has been associated with faster treatment modification and better outcomes. However, primary care doctors are the first point of care for new SLE patients or those presenting with a new complication. Moreover, given the shortage of rheumatologists in South Africa (SA) and elsewhere in Africa, primary care clinicians and general physicians are often faced with sick SLE patients and are required to make rapid therapeutic decisions. This review summarises current evidence for the treatment of SLE and its complications. We prepared this review after a PubMed search using the words 'systemic lupus erythematosus' and 'therapy'.

\section{General principles of management Education and support}

At diagnosis, patients should be offered counselling and educational material, preferably by a rheumatology nurse. Lupus support groups are very beneficial. Patients should avoid sun exposure and use a daily sunscreen (sun protection factor $(\mathrm{SPF})>50$ ).

\footnotetext{
Antimalarial therapy

The antimalarial (AM) drugs chloroquine (CQ) and hydroxychloroquine (HQ) have been used in the treatment of SLE for $>50$ years, with CQ being much more readily available in SA than HQ. Recent studies demonstrate their anti-inflammatory, antithrombotic and antilipidaemic effects via multiple molecular pathways, resulting in better control of disease activity and fewer complications (Table 1). ${ }^{[1]}$ Given the current evidence, all SLE patients should be prescribed an $\mathrm{AM}$, and clinicians should encourage compliance. The common side-effects of AM drugs are gastrointestinal, but these are usually mild and transient. More worrisome are skin hyperpigmentation and maculopathy. The latter is uncommon, affecting $2.5 \%$ of patients treated with CQ for 10 years (and $0.1 \%$ of patients using HQ); the major risk factor seems to be the cumulative dose of an AM. ${ }^{[2]}$ If diagnosed
}

early, and the AM is discontinued, the maculopathy is reversible. Therefore, patients on AMs should undergo ophthalmological assessment including fundoscopy, visual field tests and optical coherence tomography at baseline and annually after 5 years of CQ use.

\section{Corticosteroids - less is more}

Corticosteroids (CS) offer excellent control of active disease, but are responsible for most of the irreversible organ damage in SLE

Table 1. Clinical effects of antimalarial therapy in systemic lupus erythematosus

\begin{tabular}{ll}
\hline SLE disease and survival & $\downarrow$ Number and severity of lupus flares \\
& Particularly useful for joint, skin and \\
& renal involvement \\
& $\downarrow$ Damage scores \\
& $\uparrow$ Long-term survival \\
SLE onset in lupus-like disease & Delay time to fulfilment of SLE criteria \\
Thrombosis & $\downarrow$ Antiphospholipid-induced \\
& thrombosis \\
Lipid profile & $\downarrow$ Dyslipidaemia ( $\downarrow$ TG, $\downarrow$ VLDL, $\downarrow$ TC) \\
& $\downarrow$ Atherosclerosis, $\downarrow$ CV events \\
Glycaemic status & $\downarrow$ Insulin resistance and $\downarrow$ risk of \\
& diabetes, improves glucose control \\
& in diabetics \\
Infections & Antimicrobial: $\downarrow$ infections \\
& $\downarrow$ Bone mass loss \\
Pregnancy & $\downarrow$ Risk of congenital heart block in \\
& infants \\
& $\downarrow$ Number and severity of lupus flares \\
TG = triglycerides; VLDL = very low-density lipoproteins; TC = total cholesterol;
\end{tabular}


Table 2. Immunosuppressants used in SLE

\begin{tabular}{|c|c|c|c|c|}
\hline & Indication & Dose/route & Important adverse effects & Monitoring \\
\hline AM (CQ) & $\begin{array}{l}\text { - SLE } \\
\text { - Lupus-like syndromes }\end{array}$ & $\begin{array}{l}4 \mathrm{mg} / \mathrm{kg} / \text { day ideal body weight } \\
\text { (or by height in number of } \\
200 \mathrm{mg} \text { tablets/week: } \\
<154 \mathrm{~cm}, 4 / \text { week; } \\
154-174 \mathrm{~cm}, 5 / \text { week; } \\
>174 \mathrm{~cm}, 6 / \text { week) }\end{array}$ & $\begin{array}{l}\text { - Skin hyperpigmentation } \\
\text { - Maculopathy }\end{array}$ & $\begin{array}{l}\text { Screen for maculopathy annually } \\
\text { after } 5 \text { years of use or annually in } \\
\text { elderly }\end{array}$ \\
\hline CS & $\begin{array}{l}\text { Severe organ } \\
\text { involvement }\end{array}$ & $\begin{array}{l}\text { IV methylprednisolone or } \\
\text { oral prednisone } 0.5-1 \mathrm{mg} / \mathrm{kg}\end{array}$ & $\begin{array}{l}\text { Numerous comorbidities } \\
\text { (Table } 3 \text { ) }\end{array}$ & Lowest dose possible, taper rapidly \\
\hline MTX & Skin, joint & 7.5 - $25 \mathrm{mg} /$ week & $\begin{array}{l}\text { - BM toxicity } \\
\text { - Hepatotoxicity, teratogenic }\end{array}$ & FBC, AST \\
\hline CYC & $\begin{array}{l}\text { - Nephritis } \\
\text { - NPSLE } \\
\text { - Vasculitis } \\
\text { - Other severe organ } \\
\text { involvement }\end{array}$ & $\begin{array}{l}\text { IVI pulse } 10-20 \mathrm{mg} / \mathrm{kg} \text { monthly } \\
\text { (less toxic than oral CYC) } \\
\text { Euro-lupus regimen } 500 \mathrm{mg} \text { IVI }\end{array}$ & $\begin{array}{l}\text { - Teratogenic } \\
\text { - Premature ovarian failure } \\
\text { - BM toxicity, infection } \\
\text { - Malignancies }\end{array}$ & $\begin{array}{l}\text { - FBC before infusion } \\
\text { - Co-prescribe with MESNA to } \\
\downarrow \text { bladder toxicity }\end{array}$ \\
\hline AZA & $\begin{array}{l}\text { - Haem } \\
\text { - Skin } \\
\text { - Nephritis } \\
\text { maintenance }\end{array}$ & $1-5 \mathrm{mg} / \mathrm{kg} /$ day po & $\begin{array}{l}\text { - BM toxicity, infection } \\
\text { - Hepatotoxicity }\end{array}$ & $\begin{array}{l}\text { ? TPMT test before initiating, } \\
\text { FBC in first } 3 \text { - } 4 \text { weeks of therapy, } \\
4 \text {-monthly FBC and AST }\end{array}$ \\
\hline MMF & $\begin{array}{l}\text { - Haem } \\
\text { - Skin } \\
\text { - Nephritis induction } \\
\text { and maintenance }\end{array}$ & $2 \mathrm{~g} /$ day po in 2 divided doses & $\begin{array}{l}\text { - Teratogenic } \\
\text { - GI disturbance ( } \downarrow \text { dose and } \\
\text { co-prescribe with } \mathrm{H}_{2} \text {-receptor } \\
\text { antagonist) } \\
\text { - BM toxicity, infection }\end{array}$ & FBC, AST \\
\hline CYA & Haem & $3-5 \mathrm{mg} / \mathrm{kg} /$ day po & $\begin{array}{l}\text { - Hypertension } \\
\text { - Renal dysfunction } \\
\text { - Impaired glucose tolerance } \\
\text { - Hirsutism }\end{array}$ & $\begin{array}{l}\text { - Blood pressure monitoring } \\
\text { - Creatinine }\end{array}$ \\
\hline IVIG & Haem (ITP/TTP) & $2 \mathrm{~g} / \mathrm{kg}$ for 5 consecutive days & $\begin{array}{l}\text { - Thrombosis } \\
\text { - Flu-like symproms }\end{array}$ & \\
\hline Rituximab & $\begin{array}{l}\text { Refractory nephritis, } \\
\text { severe haematological } \\
\text { disease and NPSLE } \\
\text { (off-label uses) }\end{array}$ & $\begin{array}{l}500-1000 \mathrm{mg} / \text { day } 1 \text { and } \\
\text { day } 15 \text {, IV 6-monthly or at } \\
\text { relapse }\end{array}$ & $\begin{array}{l}\text { - Serious infections: } \\
\text { - Hepatitis B reactivation } \\
\text { - Progressive multifocal leuko- } \\
\text { encephalopathy }\end{array}$ & $\begin{array}{l}\text { Hepatitis B serology prior to } \\
\text { infusion }\end{array}$ \\
\hline
\end{tabular}

patients 15 years after diagnosis. ${ }^{[3]}$ The damage is proportional to both the cumulative dose of CS and the average daily dose, and even low doses $(<7.5 \mathrm{mg}$ daily) are associated with a risk of cataracts, cardiovascular (CV) disease and osteoporosis. ${ }^{[4]}$ The best practice is to prescribe CS only to patients with severe organ involvement at the lowest effective dose for the shortest duration of time possible. A recent study demonstrated that moderate doses $(\leq 30 \mathrm{mg} /$ day $)$ of CS for severe non-renal SLE were as effective and associated with fewer adverse effects than high doses. ${ }^{[5]}$ Another study demonstrated that after pulse methylprednisolone, oral CS may be omitted from an induction immunosuppressive regimen for nephritis. ${ }^{[6]}$ An understanding of currently available immunosuppressant drugs such as methotrexate (MTX), azathioprine (AZA), cyclophosphamide (CYC) and mycophenylate mofetil (MMF) is vital in a steroid-sparing approach (Table 2).

\section{Monitoring SLE patients}

For patients with inactive disease, 4-monthly visits should include a clinical examination, blood pressure measurement, urine dipstick test, full blood count, and liver transaminase for those using potentially hepatotoxic medication. Other serum markers of active disease such as complement (C3 and C4), double-stranded DNA (dsDNA), and C-reactive protein may be useful for follow-up, but do not accurately predict flares. An annual lipogram, creatinine measurement, and HIV test are recommended. Screening for antiphospholipid antibodies at diagnosis is useful. As therapy of acute SLE improves, patients live longer. Therefore, comorbidities of the disease or complications of therapy have emerged as important causes of morbidity and mortality. Preventive and therapeutic strategies are summarised in Table 3.

\section{Infections}

The combination of inherent immune dysfunction and immunosuppressant therapy, in particular CS, puts SLE patients at high risk of community-acquired and opportunistic infections. ${ }^{[7]}$ These infections contribute significantly to the hospitalisation and mortality of SLE patients, and need to be distinguished from 
Table 3. Complications and comorbidities in SLE: Prevention and therapy

\begin{tabular}{|c|c|c|c|}
\hline Comorbidity & Comments & Associations & Prevention/therapy \\
\hline Infections & $\begin{array}{l}\text { Bacterial and opportunistic } \\
\text { respiratory and urinary tract } \\
\text { infections }\end{array}$ & $\begin{array}{l}\text { - CS dose } \\
\text { - Disease activity }\end{array}$ & $\begin{array}{l}\text { - Pneumococcal (5-yearly) and influenza } \\
\text { vaccine (annually) } \\
\text { - Vigilance by patient and healthcare team } \\
\text { - AM may be protective }\end{array}$ \\
\hline Tuberculosis & Pulmonary and extrapulmonary & - CS dose & $\begin{array}{l}\text { - INH prophylaxis if moderate dose }(\geq 15 \\
\mathrm{mg} / \text { day) CS prescribed }\end{array}$ \\
\hline Atherosclerotic CV disease & Premature CV events & $\begin{array}{l}\text { - CS dose } \\
\text { - Traditional and other risk } \\
\text { factors (APLS, inflammation) }\end{array}$ & $\begin{array}{l}\text { - Physical exercise } \\
\text { - Stop smoking } \\
\text { - Low-dose aspirin } \\
\text { - Statin and AM therapy }\end{array}$ \\
\hline Hypertension & & $\begin{array}{l}\text { - CS dose } \\
\text { - Nephritis }\end{array}$ & $\begin{array}{l}\text { - Target: }<130 / 80 \mathrm{mmHg} \text { if nephritis is } \\
\text { present) } \\
\text { - ACEi or ARB if proteinuria }\end{array}$ \\
\hline Dyslipidaemia & & $\begin{array}{l}\text { - CS dose } \\
\text { - Nephrotic syndrome }\end{array}$ & $\begin{array}{l}\text { - Low threshold for intervention: SLE } \\
\text { patients are a high-risk category } \\
\text { - Target LDL cholesterol }<2.5 \mathrm{mmol} / \mathrm{L} \\
\text { - Statins and AM }\end{array}$ \\
\hline Diabetes mellitus & & $\begin{array}{l}\text { - CS dose } \\
\text { - Obestity and other features of } \\
\text { the metabolic syndrome }\end{array}$ & $\begin{array}{l}\text { - AM may be protective } \\
\text { - Oral hypoglycaemic or insulin therapy }\end{array}$ \\
\hline Osteoporosis & & - CS dose & $\begin{array}{l}\text { - Calcium and vitamin D supplement to any } \\
\text { patient receiving CS } \\
\text { - DEXA scan 5-yearly in postmenopausal } \\
\text { women } \\
\text { - Bisphosphonate therapy if osteoporosis }\end{array}$ \\
\hline Avascular bone necrosis & $\begin{array}{l}\text { Suspect if hip or knee pain, MRI } \\
\text { to detect early }\end{array}$ & $\begin{array}{l}\text { - CS dose } \\
\text { - APL antibodies }\end{array}$ & $\begin{array}{l}\text { - Bisphosphonates or core decompression if early } \\
\text { - Joint replacement if late }\end{array}$ \\
\hline Uterine cervix carcinoma & & • CYC & $\begin{array}{l}\text { - HPV vaccine } \\
\text { - Annual Pap smears }\end{array}$ \\
\hline Lymphoma & 3-fold increase in SLE & & - Thorough clinical examination \\
\hline
\end{tabular}

an SLE flare, bearing in mind that infections may also occur together with flares. Vaccination, vigilance, easy access to wellinformed clinicians and prompt antibiotic therapy are important measures. Moreover, SLE patients are at higher risk of pulmonary and extrapulmonary tuberculosis (TB); this risk is related to CS use, lymphopenia, and lupus disease itself. ${ }^{[8]}$ Clinicians need to consider the possibility of TB in any ill SLE patient.

\section{Atherosclerosis}

Patients with SLE have a 2 - 5-fold increased risk of cardiac, cerebral or peripheral arterial atherosclerosic events, and CV events are the leading cause of mortality in SLE. ${ }^{[9]}$ Traditional Framingham CV risk factors do not fully explain the extent of the risk, as inflammatory and prothrombotic mechanisms underlie this premature atherosclerosis. Encouragingly, the $\mathrm{CV}$ risk may be reduced by regular exercise, statin therapy and possibly low-dose aspirin for any patient with $\geq 1$ traditional risk factors for atherosclerotic disease, or with antiphospholipid antibodies. ${ }^{[10,11]}$

\section{Antiphospholipid syndrome}

Antiphospholipid antibodies are commonly encountered in SLE patients and are associated with a 50\% risk of thromboembolism. ${ }^{[12]}$ Despite the lack of evidence for primary prevention of thombosis and pregnancy loss, experts recommend lowdose aspirin and AMs for SLE patients with antiphospholipid antibodies, especially when other risk factors for thrombosis coexist. ${ }^{[13]}$ With regard to secondary prevention, patients with previous venous thrombosis, moderate-intensity warfarin therapy (target international normalised ratio (INR) 2.0 - 3.0) is appropriate. In the case of previous arterial thrombosis or stroke, high-intensity warfarin therapy (target INR $3.1-4.0$ ) is preferable. Very recently it has been shown that non-vitamin $\mathrm{K}$ antagonist oral anticoagulants may be safe and effective alternatives to warfarin in antiphospholipid patients with previous venous events. ${ }^{[14]}$

\section{Management of major organ involvement \\ Nephritis}

Nephritis is one of the most severe manifestations of SLE and one of the major predictors of poor prognosis. A urine dipstick test at each assessment is mandatory. An abnormal test warrants urine microscopy and a urine protein:creatinine ratio. Renal biopsy is indicated in any patient with active urinary sediment or significant proteinuria.

Treatment of lupus nephritis consists of induction followed by a maintenance phase. Induction therapy for proliferative or membranous nephritis with CS combined with an immunosuppressive agent prevents progression to end-stage renal disease. CS may be given as pulse 
methylprednisolone, or as oral CS, tapered over a few weeks to the lowest effective oral dose. ${ }^{[15]}$ There is a high rate of relapse in patients treated with CS alone. ${ }^{[16]}$ The current first-line choice of immunosuppressant is either CYC or MMF. High-dose, intermittent CYC ('the NIH regimen') or lower dose CYC (the Euro-Lupus regimen) are acceptable approaches, but in patients with severe disease (nephrotic-range proteinuria or renal impairment), and in black or mixed-ancestry patients, the high-dose CYC regimen may be preferable. ${ }^{[17]}$ In young females who have not yet completed their families, MMF may be more suitable than CYC. Rituximab or tacrolimus may be useful in cases refractory or intolerant to conventional therapies. ${ }^{[18,19]}$ Importantly, early response to therapy predicts long-term renal outcome; therefore, patients with ongoing proteinuria and active urinary sediment at 6 months should be switched to another regimen. ${ }^{[20]}$ Maintenance therapy should be with AZA or MMF for at least 3 years. Relapses are common, and diligent follow-up is important.

\section{Neuropsychiatric lupus}

Neuropsychiatric lupus (NPSLE) is another of the serious manifestations of SLE, and may be secondary to sepsis, metabolic abnormalities, and drug side-effects, or may be directly related to the SLE (primary NPSLE). Nineteen NPSLE syndromes have been recognised, including seizures, psychosis, stroke, mood disorder, transverse myelitis, cognitive dysfunction, and peripheral neuropathy. The pathogenesis of primary NPSLE is thought to be either ( $i$ ) immune-mediated inflammation or demyelination, and/ or (ii) ischaemic injury due to microangiopathy, thrombosis or emboli, frequently associated with antiphospholipid antibodies. Magnetic resonance imaging (MRI) is usually considered to be the gold standard imaging modality in the evaluation of cerebral lesions in patients with SLE, and a recent study showed that diffuse cortical MRI lesions are likely to be associated with immune-mediated inflammation, whereas focal white or grey matter hyperintensities are more likely to be ischaemic or related to vasculitis. ${ }^{[21]}$ Inflammatory syndromes are best managed with immunosuppressive therapy, whereas ischaemic events may require anticoagulation.

Moreover, SLE is a well-known risk factor for depression, anxiety and fatigue, which tend to be poorly addressed by physicians. Several studies highlight the importance of focusing on and addressing individual patient's psychosocial situations.

\section{Heart}

Myocarditis (best detected by MRI) and endocarditis are uncommon but serious complications of SLE, while pericarditis may lead to tamponade and is treated with moderate-dose CS and AMs. Refractory disease may respond to AZA, MMF, MTX, belimumab or rituximab.

\section{Cytopenias}

Anaemia is common in SLE, and may be due to anaemia of chronic disease, iron deficiency, chronic renal insufficiency or autoimmune haemolytic anaemia (AIHA). AIHA must be treated with oral CS or pulse methylprednisolone, and if refractory may require AZA, CYC, MMF or splenectomy.

Immune thrombocytopenia is an independent risk factor for increased mortality in SLE and should be treated with oral CS or pulse methylprednisolone and AMs. In refractory cases, AZA, cyclosporin, intravenous immunoglobulins (IVIGs), MMF, danazol, CYC or splenectomy may be considered.

Thrombotic thrombocytopenic purpura is a rare but lifethreatening complication of SLE, characterised by severe thrombo- cytopenia, microangiopathic haemolytic anaemia, neurological abnormalities, renal insufficiency and fever with fragmented red blood cells on peripheral blood smear. Plasmapheresis is the mainstay of treatment. Other therapies that have been used include high-dose CS, CYC, IVIGs and rituximab.

\section{Skin}

Acute and chronic skin lesions are very common, affecting $70-85 \%$ of patients, and are frequently of great concern to patients. Prompt therapy is necessary to avoid irreversible scarring, alopecia and depigmentation. All SLE patients should wear daily sunscreen ( $S P F \geq 50$ ). Treatment with AMs and topical CS is very effective. Small studies support the use of MTX, AZA, MMF, retinoids and dapsone for refractory cases. ${ }^{[22]}$

\section{Arthritis}

Arthritis is a common presenting feature of SLE, and may be under-recognised. A recent MRI study showed a high incidence of subclinical hand and wrist arthritis, with erosions not infrequently seen, which may offer an explanation for the high prevalence of arthralgias in SLE patients. ${ }^{[23]}$ Arthritis in SLE should be treated with AMs, short-term non-steroidal anti-inflammatory drugs, and low-dose $(<10 \mathrm{mg}) \mathrm{CS}$. Patients with ongoing arthritis may benefit from MTX.

\section{Pregnancy}

Because SLE is frequently a disease affecting women of childbearing age, fertility and pregnancy may be important issues. Patients should be reassured that successful full-term pregnancies are possible, and that the best time to conceive is once SLE is inactive. Pregnancy, particularly if it occurs in a patient with active SLE, may cause flares, especially worsening of lupus nephritis. CYC may affect fertility, and the risks are greatest if high cumulative doses are used ( $>15 \mathrm{~g}$ ) and when given to women $>30$ years of age. Antiphospholipid antibodies are a risk factor for miscarriage, stillbirth, pre-eclampsia and premature delivery. Fetal congenital heart block is associated with anti-Ro/SSA or anti-La/SSB antibodies.

In pregnant SLE patients, AMs prevent flares and reduce the occurrence of congenital heart block. The incidence of fetal abnormalities is very low (although most studies have evaluated HQ, which may be safer than CQ). Hence, most experts believe that, after a detailed conversation with each patient, AMs should be continued during pregnancy and lactation. Glucocorticoids, AZA, and low-dose aspirin are considered safe in pregnancy, whereas MMF, CYC and MTX are contraindicated. Low-molecular-weight heparin with aspirin is indicated in patients with antiphospholipid antibodies and previous miscarriage to reduce the risk of pregnancy loss. ${ }^{[24]}$

\section{Contraception and hormone replacement therapy}

Because of concerns of flares precipitated by exogenous oestrogens, women with SLE have traditionally been counselled against the use of hormonal oral contraceptives (OCs). Recent randomised controlled trials, however, have confirmed the safety of OCs in SLE. ${ }^{[25]}$ Because of the risk of thrombosis (both venous thrombosis with thrombo-embolism and myocardial infarction), OCs should be avoided in patients with antiphospholipid antibodies. Longterm hormone replacement therapy, although seemingly desirable in patients with premature menopause or osteoporosis, should be avoided because of the risk of mild to moderate flares and thrombosis. 


\section{Newer therapies}

Improved understanding of the pathogenesis of SLE has paved the way for the development of new biologic agents. Rituximab, a humanised monoclonal antibody targeting CD-20 receptors on B lymphocytes, is useful in refractory nephritis, severe haematological disease and NPSLE. Belimumab inhibits B-lymphocyte stimulator and has recently been approved in the USA for mild to moderate disease. Several novel agents are currently being evaluated for safety and efficacy in lupus.

\section{References}

1. Wallace DJ, Gudsoorkar VS, Weisman MH, et al. New insights into mechanisms of therapeutic effects of antimalarial agents in SLE. Nat Rev Rheumatol 2012;8:522-533. [http://dx.doi.org/10.1038/ nrrheum.2012.106]

2. Ruiz-Irastorza G, Ramos-Casals M, Brito-Zeron P, et al. Clinical efficacy and side effects of antimalarials in systemic lupus erythematosus: A systematic review. Ann Rheum Dis 2010;69:20-28. [http://dx.doi.org/10.1136/ard.2008.101766]

3. Gladman DD, Urowitz MB, Rahman P, et al. Accrual of organ damage over time in patients with systemic lupus erythematosus. J Rheumatol 2003;30:1955-1959.

4. Zonana-Nacach A, Barr SG, Magder LS, et al. Damage in systemic lupus erythematosus and its association with corticosteroids. Arthritis Rheum 2000;43:1801-1808. [http://dx.doi.org/10.1002/15290131(200008) 43:8<1801::AID-ANR16>3.0.CO;2-O]

5. Ruiz-Arruza I, Barbosa C, Ugarte A, et al. Comparison of high versus low-medium prednisone doses for the treatment of systemic lupus erythematosus patients with high activity at diagnosis. Autoimmun Rev 2015;14(10):875-879. [http://dx.doi.org/10.1016/j.autrev.2015.05.011]

tre cohort study to evaluate . Condon MB, Ashby D, Pepper RJ, et al. Prospective observational single-centre cohort study to evaluate the effectiveness of treating lupus nephritis with rituximab and mycophinolate mofetil but no ora steroids. Ann Rheum Dis 2013;72:1280-1286. [http://dx.doi.org/10.1136/annrheumdis-2012-202844] 7. Dubula T, Mody GM. Spectrum of infections and outcome among hospitalized South Africans with systemic lupus erythematosus. Clin Rheumatol 2015;34:479-488. [http://dx.doi.org/10.1007/s10067 014-2847-0

8. Hodkinson B, Musenge E, Tikly M. Osteoarticular tuberculosis in patients with systemic lupus erythematosus. QJM 2009;102:321-328. [http://dx.doi.org/10.1093/qjmed/hcp015]

9. Bartels CM, Buhr KA, Goldberg JW, et al. Mortality and cardiovascular burden of systemic lupus erythematosus in a US population-based cohort. J Rheumatol 2014;41:680-687. [http://dx.do org/10.3899/jrheum.130874]

10. Barnes JN, Nualnim N, Dhindsa M, et al. Macro- and microvascular function in habitually exercising systemic lupus erythematosus patients. Scand J Rheumatol 2014;43:209-216. [http://dx.doi.org/10.31 09/03009742.2013.846408]

11. Willis R, Seif AM, McGwin G, Jr, et al. Effects of statins on proinflammatory/prothrombotic biomarkers and on disease activity scores in SLE patients: Data from LUMINA (LXXVI), a multi-ethnic US cohort. Clin Exp Rheumatol 2014:32:162-167.

12. Somers E, Magder LS, Petri M. Antiphospholipid antibodies and incidence of venous thrombosis in a cohort of patients with systemic lupus erythematosus. J Rheumatol 2002;29:2531-2536.
13. Bertsias G, Ioannidis JP, Boletis J, et al. EULAR recommendations for the management of systemic lupus erythematosus. Report of a Task Force of the EULAR Standing Committee for International Clinical Studies Including Therapeutics. Ann Rheum Dis 2008;67:195-205. [http://dx.doi.org/10.1136/ ard.2007.070367]

14. Cohen H, Dore CJ, Clawson S, et al. Rivaroxaban in antiphospholipid syndrome (RAPS) protocol: A prospective, randomized controlled phase II/III clinical trial of rivaroxaban versus warfarin in patients with thrombotic antiphospholipid syndrome, with or without SLE. Lupus 2015;24(10):1087-1094. [http://dx.doi.org/10.1177/0961203315581207]

15. Hahn BH, McMahon MA, Wilkinson A, et al. American College of Rheumatology guidelines for screening, treatment, and management of lupus nephritis. Arthritis Care Res (Hoboken) 2012;64:797808. [http://dx.doi.org/10.1002/acr.21664]

16. Austin HA, 3rd, Klippel JH, Balow JE, et al. Therapy of lupus nephritis. Controlled trial of prednisone and cytotoxic drugs. N Engl J Med 1986;314:614-619. [http://dx.doi.org/10.1056/NEJM198603063141004]

17. Houssiau FA. Therapy of lupus nephritis: Lessons learned from clinical research and daily care of patients. Arthritis Res Ther 2012;14:202. [http://dx.doi.org/10.1186/ar3656]

18. Moroni G, Gallelli B, Sinico RA, et al. Rituximab versus oral cyclophosphamide for treatment of relapses of proliferative lupus nephritis: A clinical observational study. Ann Rheum Dis 2012;71:17511752. [http://dx.doi.org/10.1136/annrheumdis-2012-201442]

19. Mok CC, Ying KY, Yim CW, et al. Tacrolimus versus mycophenolate mofetil for induction therapy of lupus nephritis: A randomised controlled trial and long-term follow-up. Ann Rheum Dis 2014; 30 December. [Epub ahead of print] [http://dx.doi.org/10.1136/annrheumdis-2014-206456]

20. Houssiau FA, Vasconcelos C, D'Cruz D, et al. Early response to immunosuppressive therapy

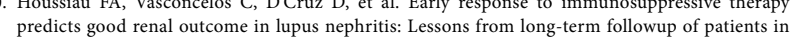
the Euro-Lupus Nephritis Trial. Arthritis Rheum 2004;50:3934-3940. [http://dx.doi.org/10.1002/ art.20666]

21. Luyendijk J, Steens SC, Ouwendijk WJ, et al. Neuropsychiatric systemic lupus erythematosus: Lessons learned from magnetic resonance imaging. Arthritis Rheum 2011;63:722-732. [http://dx.doi. org/10.1002/art.30157]

22. Winkelmann RR, Kim GK, Del Rosso JQ. Treatment of cutaneous lupus erythematosus: Review and assessment of treatment benefits based on Oxford centre for evidence-based medicine criteria. J Clin Aesthet Dermatol 2013;6:27-38.

23. Ball EM, Tan AL, Fukuba E, et al. A study of erosive phenotypes in lupus arthritis using magnetic resonance imaging and anti-citrullinated protein antibody, anti-RA33 and RF autoantibody status. Rheumatology 2014;53:1835-1843. [http://dx.doi.org/10.1093/rheumatology/keu215]

24. Empson M, Lassere M, Craig J, et al. Prevention of recurrent miscarriage for women with antiphospholipid antibody or lupus anticoagulant. Cochrane Database Syst Rev 2005;(2):CD002859. [http://dx.doi.org/10.1002/14651858.cd002859.pub2]

25. Lateef A, Petri M. Hormone replacement and contraceptive therapy in autoimmune diseases. J Autoimmun 2012;38:J170-J176. [http://dx.doi.org/10.1016/j.jaut.2011.11.002]

\section{Patient information websites}

Arthritis Foundation: http://www.arthritis.org.za/

Winelands SLE Support Group: http://wrc-lupus-support.co.za/

Two useful US lupus websites with particularly good information:

https://www.hss.edu/lupus-programs.asp

http://www.lupusny.org

A lupus social media site: http://www.mylupusteam.com 